\title{
REVISÃO SISTEMÁTICA SOBRE OS IMPACTOS DAS FERRAMENTAS DE MENTORING NAS ORGANIZAÇÕES
}

\section{ARTIGO DE REVISÃO}

LOUREIRO, Adeylson Felix ${ }^{1}$, SCATOLIN, Henrique Guilherme ${ }^{2}$

LOUREIRO, Adeylson Felix. SCATOLIN, Henrique Guilherme. Revisão sistemática sobre os impactos das ferramentas de mentoring nas organizações. Revista Científica Multidisciplinar Núcleo do Conhecimento. Ano 06, Ed. 06, Vol. 07, pp. 7288. Junho de 2021. ISSN: 2448-0959, Link de acesso: https://www.nucleodoconhecimento.com.br/administracao/mentoring-nasorganizacoes,

DOI: 10.32749/nucleodoconhecimento.com.br/administracao/mentoring-nas-organizacoes

\section{RESUMO}

Diante do contexto de mudanças na dinâmica organizacional, é imprescindível explorar ferramentas de capacitação que integram resultados mais competitivos e significativos. Portanto, essa pesquisa tem por objetivo realizar um levantamento sistemático acerca da aplicação do mentoring no ambiente organizacional, avaliando as ferramentas utilizadas nos últimos cinco anos. Para isso utilizou-se as bases de dados Google Scholar e SciELO. Essa busca gerou 27 ocorrências, das quais apenas 22 são utilizadas para revisão através da base Google Scholar. A análise desse estudo é decorrente dos artigos encontrados através dos critérios de inclusão na base Google Scholar, onde apenas 10 foram considerados aptos. Esse levantamento pôde

\footnotetext{
1 Especialista em Psicologia Organizacional, Bacharel em Administração de Empresas.
}

${ }^{2}$ Orientador. Doutorado em Psicologia (Psicologia Clínica).

RC: 88427

Disponível em: https://www.nucleodoconhecimento.com.br/administracao/mentoring-nasorganizacoes 
evidenciar que o mentoring é explorado somente por sua finalidade teórico-prática, mas não como uma ferramenta individual de aplicação.

Palavras-chave: Capacitação, Ferramentas, Impactos, Mentoria, Organizações.

\section{INTRODUÇÃO}

Diante do contexto de mudanças na dinâmica organizacional, é imprescindível explorar ferramentas de capacitação que integram resultados mais competitivos e significativos. Nesse sentido, o mentoring está sendo utilizado como canal de desenvolvimento de competências, pessoais e profissionais, a fim de ser um importante método de preparação para os novos desafios no ambiente de trabalho (BRITO et al., 2017).

Além disso, o uso de ferramentas aplicadas através desse canal possibilita o direcionamento das carreiras. Contextualizando, destaca-se a possibilidade do mentorado desenvolver uma perspectiva mais assertiva em seu desenvolvimento profissional, enfocando nos objetivos pessoais que geram resultados organizacionais (COSTA; BRUM, 2019).

Da mesma forma, é possível utilizar outras ferramentas que tem como objetivo instruir grupos de mentorados com a finalidade de transmitir conteúdos práticos acerca do conhecimento que está sendo ministrado pelo mentor. Elas são úteis quando se pretende atingir um maior número de aprendizes. Possibilitando, dessa forma, agregar maior valor de conteúdo e conhecimento (ARAÚJO et al., 2016).

Do mesmo modo, é possível destacar que o mentoring formal tem por objetivo organizar e executar metas bem definidas com o propósito de manter talentos, disseminar valores e conhecimento, viabilizando programas de sucessão de cargos e proporcionando, dessa forma, a retenção de conhecimento estratégico e valorizando o capital intelectual da organização (BRITO et al., 2017).

RC: 88427

Disponível em: https://www.nucleodoconhecimento.com.br/administracao/mentoring-nasorganizacoes 
Por outro lado, é possível verificar o diferencial estratégico do mentoring como canal de gestão do conhecimento (GC); uma vez que está intimamente ligado a fatores de alta complexidade de interação interpessoal, o que o torna um processo valioso em termos de inovação e sustentabilidade para as organizações (BARROSO; FANDIÑO; SANTOS, 2016).

Dentro dessa perspectiva se destaca a relação única de aprendizagem entre os envolvidos, podendo ser dividida em quatro fases: 1) Inicio (momento em que o processo começa); 2) Cultivo (etapa que resulta na passagem de conhecimentos); 3) Separação (fase em que ocorre uma ruptura na relação de mentoria, resultado de alterações na estrutura da organização ou comportamentos psicossociais em um ou ambos os indivíduos); e 4) Redefinição (processo que resulta na evolução da relação ou término definitivo da mentoria) (SALGUEIRO, 2019).

Entretanto, é válido ressaltar que o mentoring depara-se com vieses quando envolve o indivíduo nesse processo, já que a interação e as preferências são determinantes na escolha dos mentores e mentorados, e, muitas vezes, envolve aspectos emocionais e subjetivos nessa relação (YOUNG; CADY; FOXON, 2006).

A partir do contexto acima citado e visando um melhor entendimento a respeito do tema, essa pesquisa tem por objetivo realizar um levantamento sistemático acerca da aplicação do mentoring no ambiente organizacional, avaliando as ferramentas utilizadas nos últimos cinco anos. Além disso, procura responder a seguinte problemática: $O$ modo como o mentorado absorve as ferramentas de mentoring impacta diretamente nos resultados organizacionais?

Desse modo, essa pesquisa é justificada pela relevância que o resultado atingido pode agregar ao entendimento da aplicação e aprendizado do mentoring nas empresas, fornecendo, ainda, parâmetros de planejamento e ação. Esse trabalho está dividido em seis partes que compreendem: Introdução, como já mencionado, que aborda brevemente sobre o tema; Metodologia, que versará sobre o desenvolvimento dessa

RC: 88427

Disponível em: https://www.nucleodoconhecimento.com.br/administracao/mentoring-nasorganizacoes 
pesquisa; Fundamentação Teórica, que trará informações sobre mentoring e as ferramentas mais relevantes nesse estudo; Análise dos resultados, momento em que as informações dessa pesquisa serão reunidas e apresentadas; Considerações finais, que trará um parecer final e possíveis propostas de intervenção para futuras pesquisas, e Referências.

\section{METODOLOGIA}

Essa pesquisa tem por objetivo realizar um levantamento sistemático acerca da aplicação do mentoring no ambiente organizacional, avaliando as ferramentas utilizadas nos últimos cinco anos. Para isso, utiliza-se do método de revisão sistemática da literatura (KOLLER et al., 2014). Além disso, são explorados dados secundários de pesquisas já realizadas (MALHOTRA, 2011), conjuntamente com a estruturação das etapas de revisão que envolvem a identificação, localização, compilação e fichamento (ALYRIO, 2009).

A revisão sistemática se deve "ao processo de reunião, avaliação crítica, e sintética dos resultados de múltiplos estudos" (KOLLER et al., 2014, p. 55). Nesse sentido, os dados secundários são o melhor caminho na coleta de dados já que "as principais vantagens dos dados secundários são o tempo e o dinheiro que eles podem economizar" (MALHOTRA, 2011, p. 77), passando a contribuir na identificação, compreensão e definição do problema, desenvolver uma abordagem adequada, elaborar um modelo de pesquisa, responder a determinadas perguntas, testar hipóteses, e interpretar dados primários com maior clareza (MALHOTRA, 2011).

Por outro lado, a identificação se dá pelo reconhecimento do assunto, a localização é o momento em que se adquire as informações necessárias, a compilação é o agrupamento das informações coletadas, e o fichamento é a reunião feita de forma lógica de todo o conteúdo, respeitando as normas científicas para sua abordagem (ALYRIO, 2009).

RC: 88427

Disponível em: https://www.nucleodoconhecimento.com.br/administracao/mentoring-nasorganizacoes 
Nesse contexto, optou-se por utilizar as bases de dados Google Scholar e SciELO, adotando os critérios de inclusão: "mentoring" and "mentoria" and "ferramentas" and "organização" and "alavancagem" e "mentoria" and "ferramentas" and "alavancagem", respectivamente. Essa busca gerou 27 ocorrências, das quais, apenas 22 são utilizadas para revisão através da base Google Scholar, não houve resultados para a pesquisa feita na base SciELO. Os artigos encontrados correspondem a um período de cinco anos, a partir de suas publicações, e relevância na área objeto de estudo, até a data de 13 de maio de 2020 (KOLLER et al., 2014).

Essa pesquisa foi aprovada pelo comitê de ética e pesquisa do Centro Universitário da Fundação Hermínio Ometto sob o número 139/2020, em 13 de março de 2020.

\section{FUNDAMENTAÇÃO TEÓRICA}

Por se tratar de um levantamento sistemático acerca da aplicação do mentoring no ambiente organizacional, avaliando as ferramentas utilizadas nos últimos cinco anos, optou-se por fundamentar esse estudo utilizando as mais relevantes, dividindo essa sessão em dois tópicos. O primeiro, aborda e define o mentoring quanto a sua natureza e objetivos, em seguida, algumas de suas ferramentas são apresentadas como canais de aplicação instrumental desse processo.

\subsection{DEFININDO MENTORING}

Acredita-se que o termo mentoring (mentoria) provém de mitologia grega, onde Ulisses deixa a cargo de Mentor, seu amigo, o treinamento e instrução de seu filho antes de partir para novas campanhas militares, já que poderia ocorrer uma eventual sucessão ao seu trono (SALGUEIRO, 2019).

Nesse contexto, e trazendo aos dias atuais, o mentoring pode ser definido como o processo de interação entre indivíduos de diferentes níveis de experiência educacional e profissional, geralmente envolvendo um(a) mentor(a) (mais experiente

RC: 88427

Disponível em: https://www.nucleodoconhecimento.com.br/administracao/mentoring-nasorganizacoes 
que carrega consigo o conhecimento agregado) e seu(a) mentorado(a) (geralmente mais jovem e inexperiente que busca desenvolvimento e projeção em determinada área). Esse processo pode ser complexo e espontâneo, resultando em etapas bem definidas de aprimoramento que determinam as condições de sua aplicação (ENCONTRO, 2016).

Além disso, pode-se complementar dizendo que o mentoring é "um processo com foco no mais jovem, fazendo com que ele alavanque a sua carreira profissional, galgando posições mais elevadas, trazendo consigo a satisfação pessoal, fator esse essencial para o bom desempenho de um ambiente organizacional" (COSTA; BRUM, 2019). Portanto, é necessário apurar dentro desse processo as ferramentas utilizadas na transmissão de conhecimento utilizadas para capacitar e obter os resultados desejados durante a mentoria.

\subsection{FERRAMENTAS UTILIZADAS}

Nesse tópico é abordado algumas das ferramentas utilizadas no processo de mentoring. Compilou-se na Tabela 1 as mais relevantes encontradas durante essa pesquisa, categorizadas por item, ferramenta, característica e foco específico, como consta a seguir:

Tabela 1 - Ferramentas de aplicação em mentoring.

\begin{tabular}{|l|l|l|l|}
\hline Item & Ferramenta & Característica & Foco \\
Específico
\end{tabular}

RC: 88427

Disponível em: https://www.nucleodoconhecimento.com.br/administracao/mentoring-nasorganizacoes 


\begin{tabular}{|c|c|c|c|}
\hline 2 & Fishbowl & $\begin{array}{l}\text { Seu foco é instruir e treinar um grupo de } \\
\text { mentorados em situações específicas } \\
\text { (ARAÚJO et al., 2016). }\end{array}$ & Coletivo \\
\hline 3 & ACOLHA & $\begin{array}{l}\text { Mantém o foco do mentorado, evitando } \\
\text { que haja fuga de pensamentos. É indicado } \\
\text { para mentores iniciantes (RONSONI; } \\
\text { GUARESCHI, 2018). }\end{array}$ & Individual \\
\hline 4 & Roda da Vida & $\begin{array}{l}\text { Procura verificar pontos conflitantes na } \\
\text { vida pessoal que possa interferir nos } \\
\text { objetivos da mentoria (RONSONI; } \\
\text { GUARESCHI, 2018). }\end{array}$ & Individual \\
\hline 5 & $\begin{array}{l}\text { Avaliação } \\
\text { Comportamental }\end{array}$ & $\begin{array}{l}\text { Levanta características sobre os } \\
\text { envolvidos, afim de alinhar os perfis } \\
\text { (RONSONI; GUARESCHI, 2018). }\end{array}$ & Individual \\
\hline 6 & $\begin{array}{ll}\text { Matriz } & \text { SWOT } \\
\text { Pessoal } & \end{array}$ & $\begin{array}{l}\text { Identifica elementos que possam restringir } \\
\text { ou potencializar o processo de mentoria } \\
\text { (RONSONI; GUARESCHI, 2018). }\end{array}$ & Individual \\
\hline 7 & $\begin{array}{l}\text { Inteligência } \\
\text { Emocional }\end{array}$ & $\begin{array}{l}\text { Constituí na verificação de competências } \\
\text { emocionais, visando o atingimento de } \\
\text { metas pessoais (RONSONI; } \\
\text { GUARESCHI, 2018). }\end{array}$ & Individual \\
\hline
\end{tabular}

Fonte: Elaborado pelo autor.

Conforme apresentado na Tabela 1, a ferramenta Grow (Item 1) aborda quatro dimensões: 1) Objetivo; 2) Realidade; 3) Opções; e 4) Compromisso. Nesse contexto, o mentor busca delinear as etapas a serem seguidas pelo mentorado. Durante a fase de estabelecimento dos objetivos, procura-se especificar o que se pretende alcançar, identificando e definindo os critérios para seu atingimento. Além disso, na fase de análise da realidade, o mentor busca verificar todos os pontos da situação atual do

RC: 88427

Disponível em: https://www.nucleodoconhecimento.com.br/administracao/mentoring-nasorganizacoes 
indivíduo, observando juízos de valor, opiniões e crenças, embasando essas opiniões em fatos e identificando possíveis impactos, obstáculos e recursos disponíveis ao atingimento das metas (COSTA; BRUM, 2019).

Após verificar objetivos e realidade, é estabelecido as possíveis opções do mentorado através das alternativas encontradas. Nesse momento são formuladas as possibilidades que serão aprimoradas ou corrigidas durante a mentoria. Do mesmo modo, a fase de compromisso envolve o estabelecimento de uma atitude responsável sobre 0 alcance das metas traçadas, adotando planos de ação que envolvam as competências desejadas (COSTA; BRUM, 2019).

O Item 2 da Tabela 1 apresenta a ferramenta Fishbowl que foi concebida pela Problem Based Learning Laboratory (PBL Lab) na Universidade de Stanford (EUA), inspirada em aulas de medicina nas quais os alunos assistiam através de uma janela de vidro seus mentores, que apresentavam soluções aos problemas propostos (ARAÚJO et al., 2016).

Essa ferramenta possibilita ao mentorado apresentar sua solução, ou projeto, ao mentor, que irá avaliar pontos a serem corrigidos com base em sua experiência. Além disso, viabiliza maior transferência de aprendizado e interatividade entre os participantes, fomentando ainda, o senso crítico frente a situações-problema desconhecidas (ARAÚJO et al., 2016).

Por outro lado, a ferramenta ACOLHA, apresentada no item 3 da Tabela 1, é um acróstico que significa: A - Avaliar o cenário (busca entender o momento do mentorado); C - Compreender em detalhes (busca particionar os principais pontos da avaliação do cenário e indagar cada um separadamente); O - Observar comportamentos (questiona a atitude do indivíduo frente aos problemas encontrados); L - Levantar a importância dos ganhos ou perdas (avalia o sucesso, ou fracasso, na solução dos problemas); H - Há obstáculos? (Verifica as principais preocupações do mentorado no atingimento de metas) e A - Acionar tarefas (Lista e alinha as ações

RC: 88427

Disponível em: https://www.nucleodoconhecimento.com.br/administracao/mentoring-nasorganizacoes 
necessárias para solucionar os problemas apresentados). Esses tópicos buscam gerar hipóteses para solução de problemas que o mentor está avaliando em seu mentorado. No geral, o mentor decidirá o melhor caminho para atender as principais expectativas, desenvolvendo a capacidade de ouvir, compreender, explorar e construir questionamentos que irão nortear esse processo (RONSONI; GUARESCHI, 2018).

Nesse sentido, Veloso (2018) faz uso da ferramenta ACOLHA aplicada a um manual de acolhimento, direcionando novos colaboradores para as funções que irão desempenhar, bem como o funcionamento da empresa. Nesse manual podemos destacar o uso da avaliação do cenário e acionamento de tarefas durante a integração nessa breve mentoria, podendo ser aprofundada ao longo da carreira.

Embora as ferramentas de mentoria estejam enfocadas no perfil e análise profissional, a ferramenta Roda da Vida (Item 4 da Tabela 1) visa explorar os aspectos subjetivos (ex.: espiritualidade, saúde, lazer, intelecto, estado emocional, felicidade etc.) do indivíduo. Nesse caso, o mentor busca relacionar o grau de satisfação em vários âmbitos que possam influenciar durante o processo, tendo em mente que se trata de um ser humano em avaliação e não apenas um profissional. Além disso, essa é uma oportunidade única para estabelecer vínculo pessoal (Rapport[3]) e gerar disposição para a mudança do mentorado, o que é vital para seu aprimoramento (RONSONI; GUARESCHI, 2018).

Entretanto, a avaliação comportamental no processo de mentoring (Item 5 da Tabela 1) explora questões mais objetivas através de questionários estruturados, a fim de avaliar pontos fortes e fracos acerca de(a): a) Comunicação; b) Comprometimento; c) Relacionamento interpessoal; d) Gestão do tempo; e) Liderança; f) Trabalho em equipe; g) Agilidade e perspicácia; h) Persuasão; i) Flexibilidade; j) Desenvolvimento intelectual; k) Tomada de decisão e entrega; e I) Atitudes de empresário, que devem alinhar o mentorado aos objetivos e metas estabelecidos na mentoria (RONSONI; GUARESCHI, 2018).

RC: 88427

Disponível em: https://www.nucleodoconhecimento.com.br/administracao/mentoring-nasorganizacoes 
Conforme Rubiano (2018), é possível verificar o comportamento frente ao trabalho, às pessoas e à organização, observando o grau de intensidade do vínculo profissional com base em suas emoções e, nessa perspectiva, é possível analisar como esses aspectos se articulam com o indivíduo. Ainda nesse contexto, é esperado do indivíduo uma ação, ou conduta, correspondentes aos anseios interpessoais e organizacionais.

Contudo, há a utilização de uma ferramenta originária da área de negócios (Item 6 da Tabela 1), a Matriz SWOT (forças, fraquezas, oportunidades e ameaças). Sua principal função durante a mentoria é identificar, de forma estratégica, os elementos internos e externos do indivíduo (cenários otimistas, neutros e pessimistas) que possam restringir ou aprimorar as metas durante seu desenvolvimento. Nesse sentido, ela é mais indicada no alcance de metas mais concretas, como por exemplo, aumento nas vendas ou mesmo uma promoção para cargos gerenciais (RONSONI; GUARESCHI, 2018).

De acordo com Sultana (2017), o mentor possui quatro funções primordiais, tais como amizade (habilidade interpessoal), guia de carreira (orientador de ideias), fonte de informação (maior experiência), e guia intelectual (incentivo ao senso crítico), nesse contexto a autora destaca que a análise SWOT permite aprimorar os mentorados no que se refere aos detalhes que não são óbvios para eles, sendo entendida como um caminho simples e efetivo na qualificação e desenvolvimento de suas capacidades.

Desse modo, a inteligência emocional (Item 7 da Tabela 1) contribui com a validação e alcance de uma análise mais apurada verificando possíveis melhorias durante a mentoria. É importante ressaltar que essa competência tem ganho maior projeção no mundo do trabalho, visto que ela promove a autoconsciência, a consciência social, a autogestão e o gerenciamento dos relacionamentos (RONSONI; GUARESCHI, 2018).

Nessa lógica, a inteligência emocional pode ser compreendida como "a capacidade natural que nós, os humanos, temos de gerir nossas emoções com o objetivo de nos

RC: 88427

Disponível em: https://www.nucleodoconhecimento.com.br/administracao/mentoring-nasorganizacoes 
adaptarmos às circunstâncias do nosso ambiente; capacidade que podemos melhorar mediante a introspecção e a prática." (AGÜERA, 2008, p. 91).

\section{ANÁLISE DOS RESULTADOS}

\subsection{PROCEDIMENTO SISTEMÁTICO}

A análise desse estudo é decorrente dos artigos listados na Tabela 2. Essa tabela elenca numericamente os artigos considerados incluídos e não incluídos, bem como o ambiente (organizações) onde foram desenvolvidos.

Tabela 2 - Artigos para revisão sistemática.

\begin{tabular}{|c|c|c|c|c|}
\hline № & Artigo & Mentoria & Local & Incluído? \\
\hline 1 & $\begin{array}{l}\text { Proposta de Estrutura Organizacional } \\
\text { para uma Aceleradora de Empresas } \\
\text { de Base Tecnológica }\end{array}$ & Apresenta & $\begin{array}{l}\text { Incubadora de } \\
\text { empresas }\end{array}$ & Sim \\
\hline 2 & $\begin{array}{l}\text { Análise da produção científica sobre } \\
\text { o papel do escritório de projetos na } \\
\text { gestão do conhecimento período de } \\
2004 \text { a } 2014\end{array}$ & $\begin{array}{l}\text { Não } \\
\text { apresenta }\end{array}$ & $\begin{array}{l}\text { Pesquisa } \\
\text { bibliográfica }\end{array}$ & Não \\
\hline 3 & $\begin{array}{l}\text { Práticas e mecanismos de } \\
\text { compartilhamento de conhecimento } \\
\text { em um programa de aceleração de } \\
\text { startups }\end{array}$ & Apresenta & $\begin{array}{l}\text { Incubadora de } \\
\text { empresas }\end{array}$ & Sim \\
\hline 4 & $\begin{array}{l}\text { Diagnóstico de gestão do } \\
\text { conhecimento no laboratório aberto } \\
\text { de Brasília }\end{array}$ & Apresenta & Laboratório & Sim \\
\hline 5 & $\begin{array}{l}\text { Aceleradoras de Empresas: Um } \\
\text { Modelo Estrutural para a Criação de }\end{array}$ & Apresenta & $\begin{array}{l}\text { Incubadora de } \\
\text { empresas }\end{array}$ & Sim \\
\hline
\end{tabular}

RC: 88427

Disponível em: https://www.nucleodoconhecimento.com.br/administracao/mentoring-nasorganizacoes 


\begin{tabular}{|c|c|c|c|c|}
\hline & $\begin{array}{l}\text { Programas de Aceleração de } \\
\text { Startups }\end{array}$ & & & \\
\hline 6 & $\begin{array}{l}\text { Gestão familiar e planejamento } \\
\text { sucessório: um estudo multicaso }\end{array}$ & Apresenta & $\begin{array}{l}\text { Empresas } \\
\text { Familiares }\end{array}$ & Sim \\
\hline 7 & $\begin{array}{l}\text { A Valorização do Conhecimento: O } \\
\text { caso do programa COHiTEC }\end{array}$ & $\begin{array}{l}\text { Não } \\
\text { apresenta }\end{array}$ & Startups & Não \\
\hline 8 & $\begin{array}{l}\text { A Gestão do Conhecimento nas } \\
\text { Organizações } \\
\text { Militares Prestadoras de Serviços } \\
\text { Industriais } \\
\text { (OMPS-I) da Marinha do Brasil: o } \\
\text { papel } \\
\text { da gestão de recursos humanos }\end{array}$ & Apresenta & $\begin{array}{l}\text { Organização } \\
\text { militar }\end{array}$ & Sim \\
\hline 9 & $\begin{array}{l}\text { A atuação de incubadoras } \\
\text { tecnológicas no desenvolvimento das } \\
\text { capacidades de empresas incubadas } \\
\text {-um estudo na região do triângulo } \\
\text { mineiro e alto paranaíba }\end{array}$ & Apresenta & $\begin{array}{l}\text { Incubadora de } \\
\text { empresas }\end{array}$ & Sim \\
\hline 10 & $\begin{array}{l}\text { O coaching como ferramenta auxiliar } \\
\text { no desenvolvimento de competências }\end{array}$ & $\begin{array}{l}\text { Não } \\
\text { apresenta }\end{array}$ & $\begin{array}{l}\text { Pesquisa } \\
\text { bibliográfica }\end{array}$ & Não \\
\hline 11 & $\begin{array}{lll}\text { Programas } & \text { de aceleração } \\
\text { corporativos: motivações para } \\
\text { implementação sob a ótica da } \\
\text { ambidestria organizacional }\end{array}$ & Apresenta & $\begin{array}{l}\text { Incubadora de } \\
\text { empresas }\end{array}$ & Sim \\
\hline 12 & $\begin{array}{l}\text { Ecossistemas de Empreendedorismo } \\
\text { no Setor do Turismo: o caso da } \\
\text { Península de Setúbal }\end{array}$ & $\begin{array}{l}\text { Não } \\
\text { apresenta }\end{array}$ & $\begin{array}{l}\text { Empresas de } \\
\text { Turismo }\end{array}$ & Não \\
\hline 13 & $\begin{array}{l}\text { Reposicionamento do modelo de } \\
\text { educação corporativa no contexto da }\end{array}$ & $\begin{array}{l}\text { Não } \\
\text { apresenta }\end{array}$ & $\begin{array}{l}\text { Empresa de } \\
\text { Energia }\end{array}$ & Não \\
\hline
\end{tabular}

Disponível em: https://www.nucleodoconhecimento.com.br/administracao/mentoring-nas- 
mudança organizacional: estudo de caso de uma empresa brasileira de energia

14 Estruturação do sistema de Apresenta desenvolvimento de startups em uma aceleradora por intermédio de gestão de portfólio

15 Comunicação organizacional no Apresenta compartilhamento do conhecimento:

Entidade Não um estudo na Casa de Rui Barbosa.

16 Inovações radicais e organizações: Apresenta um estudo sobre o sistema de pública incentivos às startups através de corporate venture capital

17 Desempenho das startups/tic e as Não Incubadora de Não contribuições das aceleradoras: um apresenta empresas estudo de caso

18 Gestão do conhecimento e educação Apresenta a distância: um estudo da metodologia adotada no curso de pedagogia de uma instituição privada no noroeste do paraná

\begin{tabular}{|l|l|l|l|l|}
19 & $\begin{array}{l}\text { Coaching uma } \\
\text { contribuição à gestão hospitalar }\end{array}$ & Não & Hospital & Não \\
\hline $\mathbf{2 0}$ & $\begin{array}{l}\text { Como a gestão do conhecimento } \\
\text { influencia a melhoria da capacidade } \\
\text { absorvitiva das empresas de serviços }\end{array}$ & apresenta & Empresas de & Não \\
profissionais de contabilidade & & & \\
\hline
\end{tabular}




\begin{tabular}{|l|l|l|l|l|}
21 & $\begin{array}{l}\text { Estudo sobre as competências } \\
\text { comportamentais das lideranças } \\
\text { necessárias para atuarem com }\end{array}$ & Indústria & Não \\
grupos multigentacionais & Química & \\
\hline $\mathbf{2 2}$ & $\begin{array}{l}\text { Equidade de gêneros em rankings } \\
\text { para aferir clima Organizacional: uma } \\
\text { avaliação no contexto brasileiro }\end{array}$ & apresenta & Pesquisa & Não \\
\hline
\end{tabular}

Fonte: Scholar (2020).

Para ser incluído entre as fontes de informação listadas na Tabela 2, levou-se em consideração durante o levantamento sistemático, a aplicação do mentoring no ambiente organizacional, avaliando as ferramentas utilizadas e se o modo como o mentorado absorve as ferramentas de mentoring impacta diretamente nos resultados organizacionais (KOLLER, 2014).

Nesse processo, dos 22 artigos encontrados através dos critérios de inclusão na base Google Scholar, apenas 10 apresentaram algum fator de inclusão e são considerados aptos para análise. Entretanto, os artigos não incluídos apresentaram pouca ou nem uma informação relevante ao enfoque dessa pesquisa. Por esse motivo, os artigos foram agrupados e analisados conforme o local de desenvolvimento (KOLLER, 2014).

\subsection{ANÁLISE}

Foi observado que em organizações como incubadoras de empresas o mentoring é parte fundamental do processo de desenvolvimento de novos empreendedores. Nesse contexto, foi constatada na fase de prototipagem e apresentação de ideias do artigo 1 (Tabela 2) o que, aparentemente, pode ser compreendida como a ferramenta Fishbow[4], já que vários mentores envolvidos avaliaram os projetos de cada startup nesses moldes, indicando possíveis melhorias e adequações (BIFF; PEREIRA, 2019).

RC: 88427

Disponível em: https://www.nucleodoconhecimento.com.br/administracao/mentoring-nasorganizacoes 
Entretanto, a maior parte dos artigos que abordam as incubadoras de empresas não traz uma definição ou uso específico de ferramentas de mentoring, mas enfatizam os aspectos que geram resultados através desse método tais como troca de conhecimento, networking, capacitação, projeção em determinado mercado de atuação, parcerias em investimentos, definição do modelo de negócio, percepção da necessidade de melhorias, novas oportunidades, direcionamento para mercados já mapeados e maior foco nas metas (APPEL, 2017; CARNEIRO; ZILINKSI; COSTA, 2017; AVENA, 2018; BORGES, 2018). Além disso, a mentoria é mais acentuada no início do processo de aceleração das empresas, promovendo ainda, a imersão, o planejamento e a experimentação dos projetos com foco nas demandas das empresas patrocinadoras (TORRES, 2019).

Também foi verificado o uso de ferramentas de mentoring em laboratório, mas não houve especificação. Durante a análise desse ambiente houve apenas a menção do mentoring como canal de disseminação do conhecimento científico e reforçou sua importância dentro desse processo (MENDONÇA, 2020). Contudo, quando o seu uso é verificado em uma empresa familiar, é possível observar as mesmas características (aquisição de conhecimento, preparação e orientação fornecida por um indivíduo mais experiente), porém seu foco é direcionado ao planejamento sucessório na empresa e que esse processo é promovido por um mentor externo afim de evitar possíveis conflitos familiares. (ASATO, 2016). Além disso, não houve caracterização do uso de nem uma ferramenta.

Através da investigação realizada no estudo de uma organização militar foi possível averiguar as quatro etapas do mentoring (início, cultivo, separação e redefinição), além disso o caráter formal e informal da mentoria se mostra de grande importância para o processo, visto que ela impacta diretamente na percepção do mentorado quanto ao seu trabalho, carreira ou desenvolvimento profissional. Do mesmo modo, aponta que o mentoring propicia a retenção e ampliação do conhecimento 
organizacional (MAGALHÃES, 2017). Nesse estudo não houve menção de nem uma ferramenta específica.

Por outro lado, foi possível verificar através de uma faculdade EAD (ensino a distância) alguns elementos importantes no processo de mentoring destacando-o como uma modalidade de gestão de desempenho (não indicou uma ferramenta específica), bem como um modelador de competências para grupos, ou indivíduos, enfocando na execução e retroalimentando o processo para novas ações. Embora o mentoring tenha se adaptado a novas relações e diversificação da demanda de trabalho, esse processo é visto como um excelente canal para desenvolver a carreira de modo geral (GENTIL, 2017), porém "[...] não se pode afirmar que existe um programa de mentoring certo para todas as empresas [...]" (GENTIL, 2017, grifo nosso).

\section{CONSIDERAÇÕES FINAIS}

\subsection{A GENERALIZAÇÃO DO MENTORING}

Essa pesquisa teve por objetivo realizar um levantamento sistemático acerca da aplicação do mentoring no ambiente organizacional, avaliando as ferramentas utilizadas nos últimos cinco anos. Além disso, procurou responder a problemática sobre o modo como o mentorado absorve as ferramentas de mentoring e se elas impactam diretamente nos resultados organizacionais.

Nesse sentido, foram selecionadas algumas ferramentas existentes para balizar a análise desse estudo e apurar a eficácia delas após sua aplicação em ambientes organizacionais. Entretanto, só foi possível analisar de modo geral os resultados no uso do mentoring, como sua capacidade de disseminar conhecimento, orientar indivíduos mais jovens, canalizar o foco das metas, estreitar e expandir redes de contato e viabilizar novas oportunidades, esses fatores foram importantes no que tange aos impactos decorrentes desse processo, porém não permitiu mensurar resultados mais específicos acerca das ferramentas existentes.

RC: 88427

Disponível em: https://www.nucleodoconhecimento.com.br/administracao/mentoring-nasorganizacoes 


\subsection{PRINCIPAIS EVIDÊNCIAS}

Além disso, esse levantamento pôde evidenciar que o mentoring é explorado somente por sua finalidade teórico-prática, mas não como uma ferramenta individual de aplicação, inviabilizando o estudo sobre suas especificidades, profundidades e mensuração. Por outro lado, apresentou limitações de pesquisa já que só existem 27 ocorrências para os termos de inclusão, em português, para os últimos cinco anos através da base de dados Google Scholar. Contudo, quando os mesmos termos são verificados na língua espanhola ("mentoria" and "herramientas" and "organización" and "apalancamiento"), só é possível obter 9 ocorrências frente a 17300 na língua inglesa ("mentoring" and "tools" and "organization" and "leverage", até a data de 13 de maio de 2020). Também foi possível verificar nesse estudo que $60 \%$ dos artigos utilizados correspondem a dissertações de mestrado, revelando que o campo de pesquisa nesse assunto se apresenta escasso e restrito, mas com grande potencial exploratório.

\subsection{SUGESTÕES PARA FUTURAS PESQUISAS}

Portanto, sugere-se que as ferramentas utilizadas no processo de mentoring sejam abordadas através de estudos que verifiquem suas especificidades, profundidades, mensuração e resultados, em locais de língua portuguesa, diferenciando a amostra estudada por orientação sexual, idade, local geográfico (cultura), escolaridade, tipo de empresa e nível hierárquico nas organizações, já que o resultado desse estudo sofrerá variações dependendo do foco atribuído a ferramenta estudada no processo de mentoring.

\section{REFERÊNCIAS}

AGÜERA, Llorenç Guilera. Além da inteligência emocional: as cinco dimensões da mente. São Paulo: Cengage Learning, 2008. 248 p. Tradução de: Flor Maria Vidaurre Lenz da Silva.

RC: 88427

Disponível em: https://www.nucleodoconhecimento.com.br/administracao/mentoring-nasorganizacoes 
ALYRIO, Rovigati Danilo. Métodos e técnicas de pesquisa em administração. Rio de Janeiro: Fundação Cecierj, 2009. 281 p. Disponível em: https://edisciplinas.usp.br/pluginfile.php/2022219/mod_folder/content/0/Livro\%20M\% C3\%A9todos\%20e\%20Pesquisa\%20em\%20Administra\%C3\%A7\%C3\%A3o.\%20Ro vigati\%20Danilo\%20Alyrio.pdf?forcedownload=1. Acesso em: 07 de março de 2020.

APPEL, Gustavo Jales. Aceleradoras De Empresas: Um Modelo Estrutural Para A Criação De Programas De Aceleração De Startups. 2017. 195 f. Dissertação (Mestrado) - Curso de Administração, Centro de Ciências da Administração e Socioeconômicas da Universidade do Estado de Santa Catarina, Florianópolis, 2017. Disponível em: http://sistemabu.udesc.br/pergamumweb/vinculos/000031/00003193.pdf. Acesso em: 08 de maio de 2020.

ARAÚJO, Ulisses F.; LOYOLLA, Waldomiro Pelágio Diniz de Carvalho; GARBIN, Mônica Cristina; CAVALCANTI, Carolina Costa. Adoção Da Estratégia De Mentoria Fishbowl Em Projetos Integradores EM CURSO DE GRADUAÇÃO. Apresentação Trabalhos Científicos, [s.l.], p.1-7, 20 set. 2016. Associação Brasileira de Educação a Distância ABED. http://dx.doi.org/10.17143/ciaed/xxiiciaed.2016.00237. Disponível em:

https://www.researchgate.net/publication/308316385_ADOCAO_DA_ESTRATEGIA_ DE_MENTORIA_FISHBOWL_EM_PROJETOS_INTEGRADORES_EM_CURSO_DE _GRADUACAO. Acesso em: 04 de maio de 2020.

ASATO, Thiago Andrade. Gestão Familiar E Planejamento Sucessório: Um Estudo Multicaso. 2016. 136 f. Dissertação (Mestrado) - Curso de Desenvolvimento Local, Universidade Católica Dom Bosco, Campo Grande, 2016. Disponível em: https://site.ucdb.br/public/md-dissertacoes/22600-dissertacao-thiago-andradeasato.pdf. Acesso em: 08 de maio de 2020.

RC: 88427

Disponível em: https://www.nucleodoconhecimento.com.br/administracao/mentoring-nasorganizacoes 
AVENA, Bruno de Oliveira. Inovações Radicais E Organizações: Um Estudo Sobre O Sistema De Incentivos Às Startups Através De Corporate Venture Capital. 2018. 69 f. TCC (Graduação) - Curso de Administração, Fundação Getúlio Vargas, Rio de Janeiro, 2018.2 Disponível em: https://www.researchgate.net/publication/331257435. Acesso em: 08 de maio de 2020.

BARROSO, Bianca de Oliveira; FANDIÑO, Sérgio Baltar; SANTOS, Marcos dos. A inovação na gestão do capital humano no Brasil. Um olhar sobre o programa de mentoring como ferramenta estratégica na sustentabilidade das empresas. In: ENCONTRO MINEIRO DE ENGENHARIA DE PRODUÇÃO, 12., 2016, Juiz de Fora Mg. Anais [...]. Juiz de Fora - MG: Emepro, 2016. p. 2076 - 2084. Disponível em: http://www.fmepro.org/XP/editor/assets/EMEPRO2016/ANAISEMEPRO2016rev.pdf. Acesso em: 04 de maio de 2020.

BIFF, Américo Leonardo de Carlos; PEREIRA, Marcelo Farid. Proposta de Estrutura Organizacional para uma Aceleradora de Empresas de Base Tecnológica. Cadernos de Prospecção, Salvador, v. 12, n. 2, p. 284-300, jun. 2019. Disponível em: https://pdfs.semanticscholar.org/a451/4b0af4dcd4471a460dc13f369375e0448c11.pd f. Acesso em: 08 de maio de 2020.

BORGES, Marcilio Ribeiro. A Atuação De Incubadoras Tecnológicas No Desenvolvimento Das Capacidades De Empresas Incubadas -Um Estudo $\mathrm{Na}$ Região Do Triângulo Mineiro E Alto Paranaíba. 2018. 161 f. Dissertação (Mestrado) - Curso de Administração, Universidade Federal de Uberlândia, Uberlândia, 2018. Disponível em: http://repositorio.ufu.br/handle/123456789/21675. Acesso em: 08 de maio de 2020.

BRITO, Lydia Maria Pinto et al. Programa de mentoria: uma estratégia seminal de compartilhamento do conhecimento em uma empresa pública de energia. Race Revista de Administração, Contabilidade e Economia, [s.l.], p.209-234, 21 dez.

RC: 88427

Disponível em: https://www.nucleodoconhecimento.com.br/administracao/mentoring-nasorganizacoes 
2017. Universidade do Oeste de Santa Catarina. http://dx.doi.org/10.18593/race.v0i0.15121. https://portalperiodicos.unoesc.edu.br/race/article/view/15121. Acesso em: 04 de maio de 2020.

CARNEIRO, Mônica Ramos; ZILINKSI, Thiago Furlani; COSTA, Eduardo Moreira da. Práticas e mecanismos de compartilhamento de conhecimento em um programa de aceleração de startups. Navus - Revista de Gestão e Tecnologia, [s.I.], p. 113-123, 10 abr. 2017. Serviço Nacional de Aprendizagem Comercial / SENAC SC. http://dx.doi.org/10.22279/navus.2017.v7n2.p113-123.531. Disponível em: http://navus.sc.senac.br/index.php/navus/article/view/531. Acesso em: 08 de maio de 2020.

COSTA, Esdras da Silva; BRUM, Vinícius. Coaching e mentoring no processo de gestão de carreira: um estudo sobre a ferramenta GROW e sua aplicabilidade no contexto empresarial. Revista de Carreiras e Pessoas (recape). Issn 2237-1427, [s.l.], v. 9, n. 1, p.46-62, 2 jan. 2019. Revista Carreiras e Pessoas (RECAPE). http://dx.doi.org/10.20503/recape.v9i1.37233. Disponível em: https://www.researchgate.net/publication/330099631_Coaching_e_mentoring_no_pr ocesso_de_gestao_de_carreira_um_estudo_sobre_a_ferramenta_GROW_e_sua_a plicabilidade_no_contexto_empresarial. Acesso em: 29 de fevereiro de 2020.

ENCONTRO FLUMINENSE DE ENGENHARIA DE PRODUÇÃO, 6., 2016, Niterói. Anais [...]. Niterói: SFEPro - Sociedade Fluminense de Engenharia de Produção, 2016. 11 p. Tema: Uma contribuição para a Gestão de Pessoas. A criação de uma empresa de mentoring, utilizando o método QFD como ferramenta estratégica para a modernização do capital humano no Brasil. Disponível em: https://www.researchgate.net/publication/309650164_Uma_contribuicao_para_a_Ge stao_de_Pessoas_A_criacao_de_uma_empresa_de_mentoring_utilizando_o_metod o_QFD_como_ferramenta_estrategica_para_a_modernizacao_do_capital_humano_ no_Brasil. Acesso em: 22 de março de 2020.

RC: 88427

Disponível em: https://www.nucleodoconhecimento.com.br/administracao/mentoring-nasorganizacoes 
GENTIL, Késia Priscila Gomes. Gestão do conhecimento e educação a distância: um estudo da metodologia adotada no curso de pedagogia de uma instituição privada no noroeste do paraná. 2017. 98 f. Dissertação (Mestrado) - Curso de Gestão do Conhecimento nas Organizações, Unicesumar, Maringá, 2017. Disponível em: http://rdu.unicesumar.edu.br/handle/123456789/1085. Acesso em: 08 de maio de 2020.

KOLLER, Silvia H. et al. Manual de produção científica. Porto Alegre: Penso, 2014. 191 p.

https://www.biosanas.com.br/uploads/outros/artigos_cientificos/18/6505082c2a7c239 86651c7b1f7a4a92e.pdf. Acesso em: 07 de março de 2020.

MAGALHÃES, Angelo. A gestão do conhecimento nas organizações militares prestadoras de serviços industriais (OMPS-I) da marinha do brasil: o papel da gestão de recursos humanos. 2017. 151 f. Dissertação (Mestrado) - Curso de Gestão, Escola de Economia e Gestão, Universidade do Minho, Minho, 2017. Disponível em: https://repositorium.sdum.uminho.pt/handle/1822/46512. Acesso em: 08 de maio de 2020.

MALHOTRA, Naresh K. Pesquisa de marketing: foco na decisão. Tradução Opportunity translations. 3. ed. São Paulo: Pearson Prentice Hall, 2011. 512 p. Disponível em: https://www.docsity.com/pt/documentos/downloading/?id=4798811. Acesso em: 07 de março de 2020.

MENDONÇA, Lívia Batalha. Diagnóstico de gestão do conhecimento no laboratório aberto de Brasília. Brasília: Universidade de Brasília, 2020. 102 p. Disponível em: https://bdm.unb.br/handle/10483/23094. Acesso em: 08 de maio de 2020.

RONSONI, Marcus; GUARESCHI, Jean. Mentoria Organizacional: manual de implantação de programa interno. São Paulo: Primavera Editorial, 2018. 400 p. 
Disponível

em: https://d335luupugsy2.cloudfront.net/cms/files/52155/1552509312Mentoria_Organiza cional.pdf. Acesso em: 16 de abril de 2020.

RUBIANO, Mónica García (ed.). Actualizaciones en psicología organizacional. Bogotá: Universidad Católica de Colombia, 2018. 76 p. Colección Logos Signum. Tradução própria. https://publicaciones.ucatolica.edu.co/pdf/logos-signum-actualizaciones-en-psiologiaorganizacional.pdf\#page=25. Acesso em: 22 de abril de 2020 .

SALGUEIRO, Vitor Martins Afonso. 0 processo de mentoria e aconselhamento ferramenta para o incremento de capacidades em funções de comando na gnr. 2019. 71 f. Dissertação (Mestrado) - Curso de Estado-maior Conjunto, Instituto Universitário Militar, Pedrouços, 2019. Disponível em: https://comum.rcaap.pt/bitstream/10400.26/29690/1/TII_Maj\%20Vitor\%20Salgueiro.p df. Acesso em: 04 de março de 2020.

SCHOLAR, Google. Base de dados. 2020. Disponível em: https://scholar.google.com/. Acesso em: 13 de maio de 2020.

SULTANA, Shamima. SWOT Analysis of Mentees for Productive Mentoring in Tertiary Education: perspective bangladesh. : Perspective Bangladesh. American Scientific Research Journal For Engineering, Technology, And Sciences. S/l, p. 129-139. out. 2017. Tradução própria. Disponível em: https://asrjetsjournal.org/index.php/American_Scientific_Journal/issue/view/62. Acesso em: 20 de abril de 2020.

TORRES, Ariana Alves. Programas de aceleração corporativos: motivações para implementação sob a ótica da ambidestria organizacional. 2019. 124 f. Dissertação (Mestrado) - Curso de Administração, Universidade Tecnológica Federal 
do Paraná, Curitiba, 2019. Disponível em: http://riut.utfpr.edu.br/jspui/handle/1/4671. Acesso em: 08 de maio de 2020.

VELOSO, Carla Sofia Silva. Desde o acolhimento até à Avaliação de Desempenho, numa Empresa de Formação e Soluções Empresariais. 2018. 8 f. Dissertação (Mestrado) - Curso de Educação, Formação, Trabalho e Recursos Humanos, Universidade do Minho, Minho, 2018. Disponível em: https://repositorium.sdum.uminho.pt/bitstream/1822/59591/1/Relat\%c3\%b3rio_Carla \%20Sofia\%20Silva\%20Veloso.pdf. Acesso em: 18 de abril de 2020.

YOUNG, Angela M.; CADY, Steven; FOXON, Marguerite J.. Demystifying Gender Differences in Mentoring: Theoretical Perspectives and Challenges for Future Research on Gender and Mentoring. Human resource development review, [s.I.], v. 5, n. 2, p.148-175, jun. 2006. SAGE Publications. http://dx.doi.org/10.1177/1534484306287140. Tradução própria. Disponível em: https://journals.sagepub.com/doi/10.1177/1534484306287140. Acesso em: 29 de fevereiro de 2020.

\section{APÊNDICE - REFERÊNCIA DE NOTA DE RODAPÉ}

3. Técnica que busca gerar uma conexão íntima através da empatia.

4. Ferramenta que possui como foco instruir e treinar um grupo de mentorados.

Enviado: Janeiro, 2021.

Aprovado: Junho, 2021.

RC: 88427

Disponível em: https://www.nucleodoconhecimento.com.br/administracao/mentoring-nasorganizacoes 